\title{
CORRESPONDENCE
}

\section{Fishery reform: an economic problem}

Rainer Froese (Nature 475, 7; 2011) attributes the lack of success of Europe's Common Fisheries Policy to collusion between fisheries advisers and industry. I disagree. The fundamental problem is economics.

The only way to rebuild depleted fish stocks is to catch and land fewer fish until the stocks have recovered. That means reduced earnings for fishermen, at least in the short term. Thus, any conservation measure that is likely to work is going to hurt, and is almost certain to be opposed.

The deal on offer in Europe and elsewhere is a trade-off between short-term losses and long-term gains (larger stocks leading to higher stability, catch rates and profits). Without some mechanism to make the deal more attractive to fishermen, it is always going to be a struggle to achieve sustainable levels of fishing.

Such a mechanism is conceivable: for example, through an up-front investment in a buy-back of fishing rights, to be paid for by future licence charges or resource rental taxes. These steps are necessary to prevent future pressure on conservation measures once fishing becomes more profitable again. Direct controls on fishing effort, such as limiting the number of days at sea, are also likely to be needed. They have many advantages, especially for the regrettably common situation of inadequate stock assessments, and for reducing discarding in mixed fisheries.

Economic deadlock has bedevilled fisheries management for more than half a century. It needs to be addressed directly for any progress to be made.

John Shepherd National Oceanography Centre, University of Southampton, UK. jgs@noc.soton.ac.uk

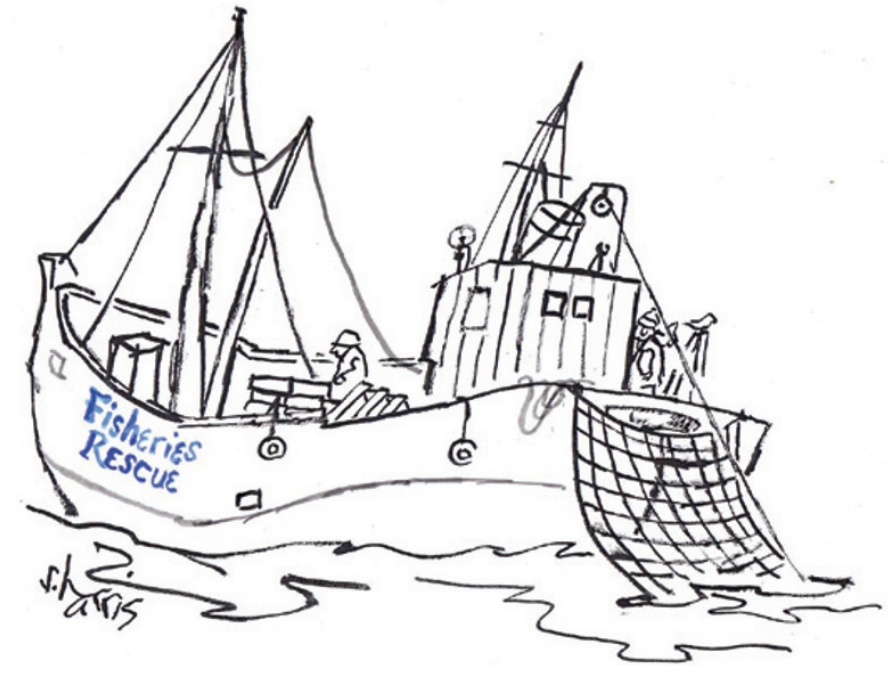

\section{Fishery reform: ban political haggling}

We applaud proposals by the European Commission to reform the Common Fisheries Policy by phasing out fish discarding, broadening multi-year speciesmanagement plans, improving data collection and moving to ecosystem-based management (Nature 475, 7; 2011). But one vital reform has been missed: bargaining over total allowable catches should be banned and decision-makers should be compelled to follow scientific advice.

Politicians have habitually overruled scientific advice on fisheries since inception of the EC policy in the 1980s, setting total allowable catches one-third higher than recommended levels. Placing short-term political expediency and industry lobbying ahead of long-term sustainability threatens food security and the health of future generations.

Science provides the best tools for maximizing immediate benefits from fishing without squandering future opportunities. Let politicians argue for their national share of what nature can provide, rather than adopting policies that undermine the biological basis of food production. Politicians must cede their power over fisheries if they are properly to serve the public interest. Bethan C. O'Leary, Callum Roberts University of York, UK. callum.roberts@york.ac.uk

\section{In defence of green economy report}

As contributors to the United

Nations Environment

Programme report criticized by

Peter Victor and Tim Jackson

(Nature 472, 295; 2011), we

stand by its claim that a green economy can grow faster than a brown economy.

Victor and Jackson argue that the report's G2 green investment scenario sets out inadequate target reductions for carbon dioxide emissions by 2050. But G2 is only one path projected for the next 40 years. The assumed technologies and costs derive mainly from International Energy Agency reports. Modelling a faster transition would require stronger assumptions about future technologies.

Contrary to the authors' implication, the analysis does not assume that the funds needed to achieve this target under a green-investment scenario would exceed those under a business-as-usual (BAU) scenario. The report explains that $\mathrm{G} 2$ was compared against a BAU2 scenario in which the same amount of investment $(2 \%$ of global gross domestic product; GDP) is allocated to existing patterns of gross capital formation (see go.nature.com/wdmgbb).

Neither does the analysis overlook different living standards between countries. The T21 global model presents global totals, and it is calibrated to reflect the past 40 years, during which the ratio of the GDP per capita in high-income countries to that in low- and medium-income countries has declined from about 22:1 in 1990 (according to the World Bank) to $15: 1$ in 2007. Even though convergence of living standards was not set as a target, the modelled scenarios do probably represent further convergence.

We cannot claim that a green economy will always grow faster than a brown economy. But the report does provide evidence to counter the long-standing view that such an outcome is unlikely, even when limited to conventional GDP as a measure. Andrea Bassi Millennium Institute, Arlington, Virginia, USA. Derek Eaton United Nations Environment Programme, Geneva, Switzerland. derek.eaton@unep.org

\section{Better provenance for biobank samples}

Health-care systems spend billions of dollars annually on biomarker research for personalized medicine. Success hinges on the quality of the biobank specimens and the data used to derive them, but a lack of quality control is polluting the scientific literature with flawed information that will take a long time to sort out (see go.nature. com/tfm8sn).

We analysed 125 papers (see go. 